IZA DP No. 7889

Skill Variety, Innovation and New Business Formation

Jolanda Hessels

Udo Brixy

Wim Naudé

Thomas Gries

January 2014 


\title{
Skill Variety, Innovation and New Business Formation
}

\author{
Jolanda Hessels \\ ESE, Erasmus University Rotterdam and Panteia/EIM
}

Udo Brixy

Institute for Employment Research (IAB)

and Ludwig-Maximilians University, Munich

Wim Naudé

MsM, University of Maastricht and IZA

Thomas Gries

University of Paderborn
Discussion Paper No. 7889
January 2014

IZA
P.O. Box 7240
53072 Bonn
Germany

\author{
Phone: +49-228-3894-0 \\ Fax: +49-228-3894-180 \\ E-mail: iza@iza.org
}

\begin{abstract}
Any opinions expressed here are those of the author(s) and not those of IZA. Research published in this series may include views on policy, but the institute itself takes no institutional policy positions. The IZA research network is committed to the IZA Guiding Principles of Research Integrity.

The Institute for the Study of Labor (IZA) in Bonn is a local and virtual international research center and a place of communication between science, politics and business. IZA is an independent nonprofit organization supported by Deutsche Post Foundation. The center is associated with the University of Bonn and offers a stimulating research environment through its international network, workshops and conferences, data service, project support, research visits and doctoral program. IZA engages in (i) original and internationally competitive research in all fields of labor economics, (ii) development of policy concepts, and (iii) dissemination of research results and concepts to the interested public.
\end{abstract}

IZA Discussion Papers often represent preliminary work and are circulated to encourage discussion. Citation of such a paper should account for its provisional character. A revised version may be available directly from the author. 
IZA Discussion Paper No. 7889

January 2014

\section{ABSTRACT}

\section{Skill Variety, Innovation and New Business Formation}

We extend Lazear's theory of skills variety and entrepreneurship in three directions. First, we provide a theoretical framework linking new business creation with an entrepreneur's skill variety. Second, in this model we allow for both generalists and specialists to possess skill variety. Third, we test our model empirically using data from Germany and the Netherlands. Individuals with more varied work experience seems indeed more likely to successfully start up a new business and being a generalist does not seem to be important in this regard. Finally, we find that innovation positively moderates the relationship between having varied experiences, and being successful in starting up a new business. Our conclusion is that entrepreneurs with more varied work experience are more likely to introduce innovations that have not only technical, but also commercial value. Our findings support the notion that entrepreneurship can be learned.

JEL Classification: L26, M13, J24, O31

Keywords: entrepreneurship, start-ups, human capital, innovation, skills

Corresponding author:

Wim Naudé

Maastricht School of Management

P.O. Box 616

6200 MD Maastricht

The Netherlands

E-mail: naude@msm.nl 


\section{Introduction}

The creation of a new business can contribute to development by fuelling competition, creating jobs, and providing new goods and services (Ács and Naudé, 2013; Braunerhjelm et al., 2010). These are amongst the societal contribution of entrepreneurs, who identify and utilize risky opportunities through the creation of a new business (Gries and Naudé, 2011). Creating a business entails a long list of tasks. The prospective entrepreneur needs to identify an opportunity, conceptualize a business plan, organize financing, location, production techniques and also market of the new business, amongst other tasks.

This variety of tasks requires much skill, hence it is not surprising that many nascent entrepreneurs fail. As a result when governments or development agencies want to stimulate new business start-ups, they most often choose to support initiatives that aim to improve the skills of prospective entrepreneurs (Bruhn and Zia, 2011; Karlan and Valdivia, 2011). Scholarly research indeed confirms that skills is an important determinant of sucessfull entrepreneurship (see e.g. Åstebro and Bernhardt, 2005; Baptista et al. 2007; Evans and Jovanovic, 1989; Kihlstrom and Laffont, 1979; Lucas 1978). As put by Kanniainen and Poutvaara (2007:676) 'people differ substantially in terms of their ability to produce a business idea, elaborate their idea, and make its way to a marketable product or service'. In a nutshell, a successful new business is the result of a 'match' between the skills of a prospective entrepreneur and opportunities.

There is a growing literature on what kind of skills an entrepreneur needs. According to Lazear $(2004,2005)$ an entrepreneur needs to be a 'jack-of-alltrades'. His argument is that the creation of a new business requires many different activities to be performed, as mentioned, so that entrepreneurs need to be multi-skilled. Also, having a variety of skills may help to succeed in bringing an innovation to the market, or to commercialize a new idea. Generalists are, in other words, better entrepreneurs than specialists in Lazear's view.

The contribution of our paper is to extend Lazear's theory in three direc-

tions. First we provide, for the first time as we are aware, a theoretical framework to link entrepreneurial skills to opportunities. In this model we illustrate that it is the interaction of opportunities, skills and innovation that result in the creation of new businesses. Second, we refine and extend 
Lazear's (2005) 'jack-of-all-trades' notion to allow for both generalists and specialists to exhibit a variety of skills as a result of their experiences and/or investments in human capital. In other words in our model entrepreneurs can have a variety of skills, even if they specialize. Our third contribution is to test our model empirically using data from Germany and the Netherlands.

We find that individuals with more varied work experience are more likely to succeed in their attempts to start a new business. Moreover being a generalist, which proxies having balanced skills, does not matter for success in starting a new business. We also establish that innovation positively moderates the relationship between having varied experience and being successful in setting up a business. Entrepreneurs with more varied work experience are more likely to propose innovations that not only have technical, but also business value. These findings support the notion that entrepreneurship can be learned and that a variety of experience matters, not only for the performance of existing firms (as in Toft-Kehler et al., 2013) but also for the success of new business start-ups.

The rest of the paper proceed as follows. In section 2 we discuss the extant literature on skills and entrepreneurship. In section 3 we propose a novel theoretical model to link variety of skills, opportunities, and business creation. We derive a number of testable hypotheses in section 4. Then, in section 5 we use a new dataset from Germany and the Netherlands to test these hypotheses. Section 6 concludes.

\section{Literature Review}

One of the most influential theories in the context of entrepreneurial ability is the theory of balanced skills, or 'jack-of-all-trades' theory of Lazear (Lazear 2004, 2005). Lazear is concerned with the individual choice between paid-employment and self-employment. In his model individuals are endowed with two skills: an individual can be a specialist, in which case he or she receives income associated with his or her best skill, or can be an entrepreneur, in which case he or she is limited by his or her weakest attribute (Lazear 2005: 652). This would imply that individuals who are especially strong in one field would tend to invest even more in this line of competence, so as to obtain the maximum benefit as a highly specialized paid employee. On the other hand those who are multi-skilled with no competence that especially stands out, would in contrast be relatively better off 
in self-employment.

Several studies have empirically tested this idea including Lazear (2004, 2005), Wagner (2003, 2006) and Silva (2007). Lazear (2004, 2005) uses Stanford alumni data (Graduate School of Business Alumni, late 1990s) and finds that those who at some point became entrepreneurs had a more varied curriculum. From this he concludes that entrepreneurs adopt a more general human capital investment profile before they enter the labor market. Furthermore he found that the likelihood of becoming an entrepreneur is higher when someone has taken on a larger number of roles with previous employers, which he derives from the number of different occupational titles one has had (Lazear, 2005). Hence those who eventually become entrepreneurs have apparently benefitted from having taken on a variety of different roles since entering the labor market. The latter may have been the result of differences in individual's endowments of general skills, or may have been due to individual's conscious human capital investments. The investment view dominates, according to Lazear (2005).

The idea that entrepreneurs are 'jacks-of-all-trades' has also been established in studies using cross-sectional data from Germany (Wagner 2003; 2006; Bublitz and Noseleit, 2013) and Canada (Åstebro and Thompson, 2011). Silva (2007) however, using panel data from Italy and controlling for unobserved heterogeneity finds no support for this theory.

Earlier studies testing the 'jacks-of-all-trades' hypothesis typically compare the skills of entrepreneurs with those of wage-employees. The idea than is that having a variety of skills helps to keep a business up and running and to survive. It could also be argued that having a variety of skills helps someone to get a business started when in the process of setting up a firm. This is a phase in which prospective entrepreneurs need to combine different resources (e.g. financing, technology and labor). Instead of answering the question why some choose to become entrepreneurs rather than wageemployees, in this paper we answer the question why some entrepreneurs succeed in establishing a business, when many try but do not succeed.

Lazear (2005) considers those who initially established the business as entrepreneurs as these individuals have usually been responsible for the conception of the basic product, hiring the initial team, and obtaining at least some early financing. Thus, the acts or transactions needed to establish a business and get a business up and running are seen as entrepreneurial. Spulber (2009) goes even further by defining an entrepreneur as someone 
who establishes a business, which is what makes them different from other economic actors. He distinguishes between the decision to become an entrepreneur and the actual foundation of the business. Being an entrepreneur lasts from the decision to set up a business to the moment that the business is actually founded. During this period the entrepreneur devotes resources and efforts to establishing the business. Once an individual succeeds in establishing a firm he is no longer an entrepreneur but the owner of the firm. The established firm is now a new independent economic actor with own objectives distinct from those of the owner, while the objectives of the entrepreneur are interconnected with those of the start-up during the phase of firm foundation. We focus on whether those entrepreneurs who made a decision to start up a new business are more likely to succeed when they are multiple skilled.

Success in getting a new business founded is by no means guaranteed. Startup attempts may turn out to be unfeasible and may be abandoned, even if they were planned in advance (Lazear, 2005). This selection during the process of starting-up a firm is by no means needless as it helps to single out projects that are promising. A high proportion of business fail in the first months after start-up, sometimes described as due to the 'liability of newness' (Freeman et al. 1983, Brüderl and Schüssler 1990). These high rates of firm closures show that this selection actually still is not efficient enough.

Two earlier studies have investigated whether the number of fields in which an individual has experience matter for start-up success. These measured success according to the number of gestation activities completed (Stuetzer et al., 2012 and Stuetzer et al., 2013a;2013b). They found that entrepreneurs with a broad set of skills (which they term 'skill balance') complete more gestation activities. Toft-Kehler et al. (2013) investigated the impact of experience on the financial performance of existing firms using Swedish data, and found that the firms headed by owners/ managers with more varied experience tend to perform better. It remains unclear, however, whether skills and variety of experiences contributes to start-up success.

Lazear (2005) argued that it is not the sheer number of skills mastered alone that makes people prefer to become self-employed or not, but that it also depends on the balance of these skills. There is some tension in this idea because it is clear that entrepreneurs will often need to be specialists when the demand for more specialist goods are higher, and /or where high rates of innovation are required to enter markets (so that unique goods or services 
can be developed that needs specialist knowledge, e.g. in information and communication technology).

While Lazear (2004, 2005) equates mastering skills in various areas with being a generalist we deviate from this by proposing that those who master various skills can still be specialists (and that these entrepreneurs could in fact be more innovative than specialists without varied skills or generalist entrepreneurs without specialist knowledge). The mastering of various skills can result from a deliberate human capital investment strategy based on the recognition that certain skills are required for being an entrepreneur, whether one is a specialist or more of a generalist. Therefore we propose to make a distinction between the amounts of variety in work experience (skill variety), and whether someone is more of a generalist or more of a specialist (skill balance). While the first captures variety in skills the later proxies the extent of balance of the skills one possesses. One can have a variety of skills but still be a specialist, which is not accounted for in Lazear's model (Lazear, 2005). We allow for individuals to both invest in a variety of skills and still be a specialist as they mainly excel in one skill. While a specialist in Lazear's model only invests in one of the two skills, but not in both, in reality individuals may invest in more than one skill, while they can still be mainly specialists. We propose that in particular skill variety will contribute to success in establishing a business. A varied or broad skill set has been associated with higher entrepreneurial skills relevant for setting up a business (Stuetzer et al., 2013b) and with completing a larger number of gestation activities during the period when one attempts to establish a business (Stuetzer, et al.,2012).

Lazear (2005) further argues that multi-skilled entrepreneurs may have an advantage when it comes to introducing an innovation to the market because it is easier to innovate "when the entire situation can be seen" (Lazear, 2005: 661). Thus, specialists may be at a competitive disadvantage to those that have a variety of skills in particular when attempting to bring a new innovation to the market. While a technical specialist may be excellent at developing some new device, this does by no means guarantee that this device will be commercially viable. To be successful as an innovative entrepreneur, business relevance is needed; technical soundness alone is not enough (Lazear, 2005: 661). Those with a varied skillset are likely to be better in developing new products or services that have actual business value and therefore skill variety may help to succeed in bringing an innovation to the market, or to commercialize a new idea. Lazear (2005) further argues that this may apply to product innovation but also to the use of business 
process innovation. Entrepreneurs with skill variety may be better at using a new business process that allows firms to beat the competition. To test this idea that innovation and skill variety matter we also attempt to capture in this paper the interaction between an individual's experience and skills on the one hand, and the attempt to innovate by introducing a new product and/or service or by introducing a business process innovation. As Lazear (2005) did not test this prediction a contribution of this paper is to do so. Before doing so, we propose in the next section a theoretical framework to better understand the relationship between skills variety and entrepreneurial start-up outcomes.

\section{Modelling Skills Variety and Balance and New Business Creation}

As mentioned, entrepreneurs are individuals who spot and use opportunities to create new businesses. Their success depends on their skills and the availability of opportunities that matches their skills. Lazear (2005) argued that those with more generalist skills will fare better than those with more specialised skills in creating a new business firm. In this section we formalize this idea by linking skills variety and entrepreneurship with opportunities. Our basic idea of linking skills variety with new business creation through the identification and use of opportunities is based on labour economics' matching models. In these models, various 'frictions' prevent a matching of vacancies with labourers' skills giving rise to unemployment. We use this idea to describe the skills profile of latent and nascent entrepreneurs as determining the extent of their effort to search for opportunities and overcome frictions in their utilization. As stated previously, our key hypothesis, following Lazear (2005), is that entrepreneurs with a variety of skills are more likely to create new businesses - in our model because such entrepreneurs are more likely to find a "match" with an opportunity. To model the matching of opportunities and business ideas we use basic concepts of matching theory as suggested e.g. by Pissaridis (2000) for labor markets and transfer them to the entrepreneurial market entry decision, following first steps in this direction by Gries and Naudé (2011).

We present our model in five sub-sections or stages. First, we describe the pool of entrepreneurial talent in our economy, distinguishing between latent, nascent and existing entrepreneurs. Second, we introduce the set of opportunities for creating new businesses, making a distinction between 
opportunities that require innovation, and more informal, less productive opportunities. Third, we explain how the former concepts of entrepreneurs and opportunities can be linked to result in new business creation as a match between the set of entrepreneurial skills and opportunities. Fourth, we elaborate on the distribution of various skills and business success. Fifth, we derive the equilibrium outcome in our hypothetical economy, from which two testable hypotheses are generated.

\subsection{Entrepreneurs}

Most new businesses are created by entrepreneurs. Within our model we distinguish between active entrepreneurs $n$ and nascent entrepreneurs $u$. In contrast to the active entrepreneur the nascent entrepreneur is in the beginning stages of establishing a business, and may still be in a phase of evaluating an opportunity. Nascent entrepreneurs are defined according to the GEM definition as those who are actively taking steps to set up a new business (for a detailed definition including precise questions asked see Parker (2009: 8)). The concept of nascent entrepreneurship has the advantage that it is neither prone to a survival bias nor to a hindsight bias. According to Parker (2009), however, a major disadvantage is that not all start-ups are preceded by a period of planning, but are rather spontaneously founded. This would imply a certain underestimation of the number of startups. This could be offset by the fact that only a part of all planned start-ups, however, are eventually started. It is difficult to define a precise moment for when exactly someone has become a nascent entrepreneur. Often there is no exact point in time at which someone becomes a nascent entrepreneur rather it is a gradual process where one step follows another. Furthermore, it is difficult to observe the exact moment of a firm's inception or success in setting up a business (Katz and Gartner, 1988; Reynolds and Miller, 1992; Carter, Gartner and Reynolds 2004). Here inception is based on self-assessment of the nascent entrepreneur on whether the new venture is operational or not.

Having made the distinction between nascent and active entrepreneurs, it follows that the total entrepreneurial potential in the economy, $E$, is the sum of active and nascent entrepreneurs, which can be written as $E=n+u$. 


\subsection{Opportunities}

In order to create a new business, nascent entrepreneurs evaluate their startup opportunities. Opportunities are exogenously given and exist independently of entrepreneurs. $\Omega$ represents the total number of potential new business opportunities in the economy. These opportunities can be divided into three different groups. (i) Opportunities already taken, which lead to the total of $n$ active entrepreneurs and their start-up firms, (ii) a number $\omega$ of unrealized profitable opportunities ready for being taken by a nascent entrepreneur on the lookout, and (iii) there are unrealized but idle (or yet unproductive) opportunities available, denoted by $\delta$.

These could be temporary or informal opportunities which are at present not lucrative, such like self-employment and survivalist-type activities. Thus the total number of start-up-opportunities can be written as $\Omega=n+\omega+\delta$.

\subsection{New Business Creation as a Match}

At the time when the nascent entrepreneur spots and then utilizes an opportunity that matches their skills a business is founded. The number of new firms that start as the result of such matching per period is denoted by $\mathcal{M}$. In aggregate this matching rate - or new business creation rate - will be determined by three factors: (i) the specific conditions in a particular market segment (including the business environment) that affect the efficiency $\mu$ of a matching process between a product profile and opportunities; (ii) the extent of unrealized profitable opportunities, $\omega$ in relation to the number of nascent entrepreneurs trying to spot these opportunities, and (iii) the nascent entrepreneurs' skills variety that positively affects the search and development effort for finding opportunities $\eta$.

The aggregate effective search and development effort as a function of skills variety is hence $\eta u$. Depending on the extent and variety of skills the effort of nascent entrepreneurs may vary considerably as frequently stated in the related literature. An important point is that the type of skills (skills variety) interacts with the local environment or specific market conditions so that the new business creation rate in a country is not only the result of entrepreneurial skills, or only the result of the business environment - both matter, and in fact the business environment and specific market conditions may determine the nature of opportunities which again will determine which 
skills will be better rewarded. A practical policy implication that follows is that entrepreneurial education and business environment reform need to be tackled jointly and in coordinated fashion to result in more and better matches between skills and opportunities.

A theoretical implication that follows is that entrepreneurs with a variety of skills may also specialize due to the demands of the environment / nature of opportunities that they spot. For instance, if nascent entrepreneurs are in a market that demands more specialized and differentiated products, this may encourage innovation and specialization. Hence market matching efficiency $\mu$ is affected by the degree of specialization in a market. More specialized goods have a more precise profile and nascent entrepreneurs find a match more easily. In a specialized market an innovative product variation will be easily identified and such an innovation will more easily find customers who benefit from the innovative idea. In the next section we will discuss in more detail the endogenous decision for search intensity and relate this decision to the entrepreneur's skills variety and search and information costs as well as to the matching efficiency of a specific market. After having introduced the determinants of the matching process the matching (and hence start-up) rate, $M$, can be specified. Throughout the paper we will assume linear homogeneity of the matching function. Hence the effectiveness of the matching process is not a matter of the size of the economy, but rather of market specific conditions $\mu$ combined with the variety of skills that determines search effort and the start-up rate.

For computational simplicity we will model the matching-function as a Cobb-Douglas function $\mathcal{M}=\mu M=\mu \omega^{\beta}(\eta u)^{1-\beta}$. Hence, the probability of a successful new firm start-up is $\frac{\mu M}{u}=\mu m$.

\subsection{Optimal Search and Survival Effort, Matching, and Firm Failure}

We can now bring the previous three building blocks together to link new business creation with skills through the search and development effort it enables. At the individual level, any nascent entrepreneur $i$ will have to make some search and development efforts described by the effort $\eta_{i}$ to identify and develop a new business opportunity. As mentioned the collecting of information and searching for opportunities is costly. The search and development cost per unit of effort of the nascent entrepreneur is denoted $c_{i}$. 
In order to safeguard their firms' survival, active (existing) entrepreneurs will have to invest a certain survival effort, $\psi_{i}$. The optimal search and development effort to enter the market and the optimal survival effort to stay in the market, results from the maximization of the entrepreneurs' net present value $^{1}$. Hence we have (i) nascent entrepreneurs searching and implementing opportunities to start a new business, and (ii) active entrepreneurs trying to stay in business (be successful).

i) Nascent entrepreneurs: A nascent entrepreneur is in the early stages of thinking about starting a business and evaluating opportunities to start-up a firm. Net present value of all activities of this state is $W_{i}$ and contains current wage income $w_{i}$ minus search $\operatorname{costs} c_{i}$ multiplied by the search effort $\eta_{i}$ plus the expected extra entrepreneurial income in case a prosperous opportunity is spotted and realized as a lucrative new start-up enterprise.

In order to turn to a more detailed modeling of the nascent entrepreneurs' search and development costs we now modify the entrepreneurial matching model introduced by Gries and Naudé (2011) and apply it to the described problem. As a first step we argue that skill variety determines search costs. Marginal search $\operatorname{costs} c_{i}$ are a function of some given costs which we normalize to one and the variety of experiences. The idea is that the variety of work experiences gives insights into the functioning and thinking of the potential costumer side. If a nascent entrepreneur worked at many firms or positions before he or she will be able to more easily address the relevant items and hence lower his or her search costs. Similar, if a nascent entrepreneur is e.g. an engineer (with originally human capital in engineering) that has to place his product in the market (requiring a marketing skill), finance the start-up loans (requiring financial knowledge), be informed about legal and labor law restrictions (have knowledge on law issues), pay taxes (have knowledge on tax laws) and manage his firm organization (have organization skills and methods) he or she must be able to handle many very different tasks on his own with low learning costs. Only when his or her firm is growing he or she may be able to divide these specific fields of activities and allocate specialists to them. Hence the variety of work experiences can be expected to clearly matter for the costs of finding and implementing opportunities

1 We can also introduce unemployed persons searching for opportunities while still on welfare benefits, but for the sake of tractability we abstract from this possibility for now. 
and the success of a start-up. In our model, each field $j$ of experiences saves learning costs and adds as a costs reducing element of entrepreneurial human capital to individual search productivity with the effect of $h_{j}$. Hence total marginal search and development costs are a reverse of entrepreneurial human capital consisting of the number of work experiences of entrepreneur $i$ and hence of the nascent entrepreneurs skill variety $\bar{e}_{i}$ :

$$
c_{i}=\left(\sum_{j=1}^{\bar{e}_{i}} h_{i j}\right)^{-1}
$$

The larger the number of different work experiences (the larger the variety) the more productive is each unit of search effort and the lower are the marginal costs of search activities. The variety of abilities matters as the nascent entrepreneur is familiar with more components of the business activity.

Further, denoting $V_{i}$ as the expected value of entrepreneurial income, then the general expected extra entrepreneurial income $\Delta_{i}$ can be written as

$$
\Delta_{i}=V_{i}-W_{i}
$$

However, being a nascent entrepreneur this extra income is only realized when finding the opportunity to start-up. Hence for a nascent entrepreneur the expected extra income is $\Delta_{i}$ times the probability of matching and finding an opportunity. As argued in the previous section, this probability is $\mu m_{i}$. As individual efforts determine the matching probability $m_{i}\left(\eta_{i}\right)$ for a given discount rate $r$ we obtain

$$
r W_{i}=w_{i}-\left(\sum_{j=1}^{\bar{e}_{i}} h_{i j}\right)^{-1} \eta_{i}+\mu m_{i}\left(\eta_{i}\right) \Delta_{i}
$$

ii) Active entrepreneurs: As an active entrepreneur is continuously working to keep his or her firm going, the net present value of being such an entrepreneur $V_{i}$ is

$$
r V_{i}=v_{i}-\gamma_{i} \psi_{i}-\phi_{i}\left(\psi_{i}\right) \Delta
$$

In this second state the profit flow is $v_{i}$. In order to stay in the market the entrepreneur decides to invest $\gamma_{i} \psi_{i}$ with effort $\psi_{i}$ and marginal costs 
$\gamma_{i}$. The transitory and dynamic character of markets and role of the entrepreneurs abilities for founding and running the company are reflected by these required investments and efforts. However effort towards firm survival and investments do not guarantee that a firm will not fail and entrepreneurs have to consider the likelihood of firm failure denoted by $\phi_{i}$. Taking the perspective of an individual entrepreneur $i$ however reveals that her survival efforts $\psi_{i}$ may reduce the likelihood of firm failure $\phi_{i}$ which follows $\phi_{i}=\phi_{i}\left(\psi_{i}\right), \phi_{\psi_{i}}:=\frac{\partial \phi_{i}}{\partial \psi_{i}}<0, \phi_{\psi_{i} \psi_{i}}:=\frac{\partial^{2} \phi_{i}}{\partial \psi_{i}^{2}}>0$.

Hence, an entrepreneur having a particular skill variety and experience has the choice to invest with search effort $\eta_{i}$ and with survival effort $\psi_{i}$ in order to increase the chance of finding a match and to lower the probability of a firm failure. No matter what state an entrepreneur is in, she can maximize the expected income. Thus the following maximization exercise will give us the optimal search effort and the survival effort:

$$
\begin{gathered}
\max _{\eta_{i}}: \quad r W_{i}=w_{i}-c_{i} \eta_{i}+\mu m_{i}\left(\eta_{i}\right) \Delta \\
\max _{\psi_{i}}: \quad r V_{i}=v_{i}-\gamma_{i} \psi_{i}-\phi_{i}\left(\psi_{i}\right) \Delta
\end{gathered}
$$

We obtain from the first order conditions (F.O.C) an optimal search effort $\eta^{*}$ and optimal survival effort $\psi^{*}$ by using the implicit function theorem ${ }^{2}$

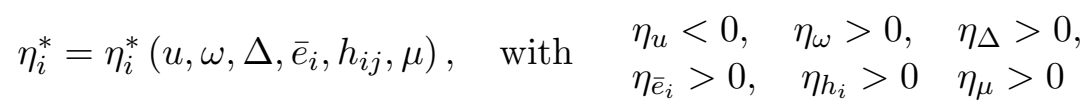

$$
\begin{aligned}
& \psi_{i}^{*}=\psi_{i}^{*}\left(\Delta, \gamma_{i}\right), \quad \text { with } \quad \psi_{\gamma_{i}}<0, \quad \psi_{\Delta}>0
\end{aligned}
$$

Most interesting, partial derivatives $\eta_{\bar{e}_{i}}>0$ and $\eta_{\mu}>0$ suggests that search effort will increase with a larger skill variety $\bar{e}_{i}$ and with a higher matching efficiency $\mu$ which may be due to more specialized and innovation driven markets.

\subsection{Aggregate Equilibrium Outcome}

As we assumed symmetry across all entrepreneurs, we can now focus on the aggregate equilibrium. We start with the representative wealth differential

2 See appendix 1. 
$\Delta$ of both wealth levels ( $W$ and $V$ ) corresponding to being a nascent entrepreneur (in the process of evaluating an opportunity), or being an active entrepreneur (trying to stay in business). We obtain an implicit relation for this wealth differential by

$$
\Delta=\frac{v-w+c \eta(x)-\gamma \psi(\Delta, \gamma)}{r+\phi(\psi(\Delta, \gamma))+\mu m(\eta(x))}
$$

with $x$ defining the vector $x=(u, \omega, \Delta, \bar{e}, h, \mu)$.

Next, we calculate the difference in new start-ups and firm failures that will describe the market dynamics. From the above we know that on aggregate the number of firm failures is $\phi n$, and the total of matched new business start-ups equals $\mu M$. Hence net creation of firms is $\dot{n}=\mu M-\phi n$. The corresponding stationary flow equilibrium condition is:

$$
\dot{n}=0 \quad \Leftrightarrow \quad \mathcal{M}=\mu M=\phi n
$$

In stationary equilibrium the number of new firms will equal the number of firm failures.

Eventually we want to determine the aggregate stationary number of businesses. Hence, we have to account for the dynamics of opportunities in the economy. In this model this dynamics are covered by two probabilities denoted $p$ and $q . p$ is the probability that profitable opportunities - no matter if actively used or unused - turn unprofitable, whereas $q$ denotes the probability of once idle opportunities becoming lucrative. $p$ and $q$ may depend on exogenous factors such as having a boom or bust during a business cycle which we do not consider here. Hence the dynamics (rate of change) in idle start-up opportunities is $\dot{\delta}=p(\omega+n)-q \delta$, and the stationary flow equilibrium for opportunities is ${ }^{3}$

$$
\dot{\delta}=0 \quad \Leftrightarrow \quad \omega=\frac{q}{p+q} \Omega-E+u
$$

The equations (1), (2) and (3) form a system with three endogenous variables $(u, \omega, \Delta)$. The considered determining factors in this system are skill variety $\bar{e}$ and market specific conditions represented by the matching efficiency $\mu$.

$\overline{3}$ We use the definition $\Omega=n+\omega+\delta$ to substitute for $\delta$. 
Both factors affect search effort $\eta$ and eventually the aggregate start-up rate in this economy.

$0=F=\phi\left(\psi^{*}\right)(E-u)-\mu M\left(\omega, u, \eta^{*}\right) \quad$ stationary matching equilibrium

$0=G=\Delta\left(r+\phi\left(\psi^{*}\right)+\frac{\mu M\left(\omega, u, \eta^{*}\right)}{u}\right)-v+\gamma \psi^{*}+w-c \eta^{*} \quad$ wealth diff.

$0=H=\omega-\frac{q}{p+q} \Omega+E-u \quad$ supply of profitable opportunities

From this system of equations we can derive Proposition 1.

Proposition 1: The economy [the system of equations F, G, H] has a stationary matching equilibrium solution of new business creation and business failure, and hence a stationary number of nascent entrepreneurs $u^{*}$, unrealized but profitable opportunities $\omega^{*}$ and a stationary differential of entrepreneurial and labor wealth $\Delta^{*}$, as long as $\frac{q}{p+q} \Omega-E>0 \rightarrow \omega>u$.

$$
u^{*}=u^{*}(x), \quad \omega^{*}=\omega^{*}(x), \quad \Delta^{*}=\Delta^{*}(x),
$$

where $x=(\mu, \bar{e}, h)$ represents the vector of considered exogenous variables.

Proof: See Appendix 2.

Proposition 1 means that there is a stable number of businesses in the economy in equilibrium. Being confronted with a constant number of firms we can investigate to what degree opportunities or entrepreneurial potential in this economy could be utilized. The fact that we can determine the stationary wealth premium $\Delta^{*}$ for a representative entrepreneur is another feature of Proposition 1. Knowing this information means that one can deduce the economy's efficiency with respect to entrepreneurial activities. Assuming a perfect and risk neutral market economy there is little need for an extra premium to become an entrepreneur. Therefore, we describe the market as a location (or institutional framework) which may or may not be fulfilling its purpose efficiently. 


\subsection{Hypotheses and Comparative Statics}

So far the model argued that skill variety and various work experiences may affects information, transaction and search costs that are a major element to find opportunities and to start up a firm. We can now show that the model implies that an increase in skill variety matters for success and increase the start-up rate (as defined here as the percentage rate of new firms in relation to existing firms).

Hypothesis 1: An increasing variety of work experiences, de $>0$, will reduce information and search costs and make nascent entrepreneurs more confident to succeed, leading to (i) an increasing start-up effort $d \eta>0$, and (ii) an increase in the matching and the equilibrium startup rate $\varepsilon=\frac{\mathcal{M}}{n}$, as long as $\frac{q}{p+q} \Omega-E>0 \rightarrow \omega>u$,

$$
\frac{d \eta}{d \bar{e}}>0, \quad \frac{d \varepsilon}{d \bar{e}}>0
$$

Proof: See Appendix 3.

As a result entrepreneurs with a variety of work experiences should be more successful in the start-up process.

A second hypothesis can be also derived from our model. If nascent entrepreneurs are in a market with more specialized goods demand and supply profiles become more precise. Entrepreneurs developing an innovative product even may have clear ideas of specific costumers and their needs. That is, in contrast to a product development of a rather unspecified product for an anonymous market new innovative entrepreneurs in specialized markets have a clear idea of costumers and their specific needs. They will be able to introduce a specific innovative product variation to the particular target group. For example if an engineer develops a new electronic component for a niche market she will be able to give a very precise description of the product innovation. She may even have developed the innovative product for a group of potential costumers she had in mind; and she may have taken care of specified elements already during the R\&D process. Hence, under this market conditions the product profile of the innovation can be more easily compared with a product profile a costumer would like to have, such 
that profiles easily match or not. As a result the efficiency of the matching process is comparably high. Markets with specialized products have a higher matching efficiency when innovations appear and hence the matching efficiency increases in such markets. Therefore this discussion results in the following testable hypothesis:

Hypothesis 2: If in specialized markets innovations and innovative elements can be easily identified such that matching efficiency rises, $d \mu>0$, and as a result, (i) start-up effort of innovative nascent entrepreneurs $\eta$ increase, and (ii) the matching and start-up rate $\varepsilon=\frac{\mathcal{M}}{n}$ improves

$$
\frac{\partial \eta}{\partial \mu}>0 \quad \frac{\partial \varepsilon}{\partial \mu}>0
$$

Proof: See Appendix 3.

In the next section we attempt to confront these hypotheses with empirical data.

\section{Empirical Study}

\subsection{Data and Key Variables}

In the previous section we derived two testable hypotheses. In this section we try to test these. First however a word about the data and key variables.

\subsubsection{Nascent entrepreneurs}

Nascent entrepreneurs (those in the process of starting up a business) were identified from the adult population survey of the Global Entrepreneurship Monitor (GEM) conducted in spring 2006 and spring 2007 in both Germany and the Netherlands. A follow up survey was held among these nascent entrepreneurs approximately one year after the adult population surveys. In this follow up survey it was assessed whether the nascent entrepreneurs 
had succeeded in setting up a business, whether they were still in the process of setting up their firm or whether they abandoned their start-up attempt. This three-stage variable for success in firm foundation or "start-up success" is the dependent variable in our models. Table 1 shows the numbers of respondents reached for each of these three categories.

Information on whether the business was founded is based on follow-up interviews that were conducted one year after the GEM-screening interviews. We cannot take account of the fact that during the first screening in which the nascent entrepreneurs were identified some start-up initiatives were already more advanced than others.

Table 1: Status of the business start-up attempt one year after first screening

\begin{tabular}{lcc}
\hline & Number & Percent \\
\hline Business founded & 109 & 57.7 \\
Postponed & 40 & 21.2 \\
Given-up & 40 & 21.2 \\
\hline Total & 189 & 100.0 \\
\hline
\end{tabular}

\subsubsection{Innovation}

We capture innovation by product (or service) innovations and process innovations. First, we distinguish between those who attempt to introduce new products or services to the markets and those who introduce already existing goods or services. Second, we distinguish those who make use of new technologies from those who do not. While the former is about introducing products or services that are new to customers, the latter reflects using a new technology, which e.g. may make it possible to introduce something that already exists at lower costs and thus can make it possible to attract new, more price-sensitive customers (OECD 2005).

The measures that we use for product innovation and process innovation are both based on questions contained in the GEM adult survey. Individuals identified as nascent entrepreneurs are asked whether the planned business will offer a novel product or service or all, to some or to none of its (expected) customers. We create a dummy for product innovation getting the value 1 in case an individual offers a product or service that is new to all or some customers. A process innovation is identified by the GEM adult population 
survey population question regarding the age of the technology that is to be used. We construct a dummy variable that takes the value of one when the interviewees use technologies that have been available for five years or less and zero otherwise.

More than half of all nascent entrepreneurs in our sample claim that the service or product they intend to supply is at least new to some customers, including 13 percent that even claim it new to all customers. These shares are in line with results from the US PSED (Panel Study of Entrepreneurial Dynamics) studies, where 19 percent of all nascent entrepreneurs in 2006 state that no existing firms already offer (the) same product or (the) same service to the (expected) customers (Hurst and Pugsley, 2011: 94). The share of nascent entrepreneurs using new production technologies is notably smaller than those with product or service innovations. Just a quarter of all nascent entrepreneurs claim to use a technology that is younger than six years.

\subsubsection{Skill variety and balance}

Lazear (2005) chose a retrospective design by analyzing the employmentbiographies of Stanford graduates via a job history panel to examine the variety and the degree of specialization of each graduate. For him the main measure of the number of skills of a person is the number of different occupations a person has had before. Lazear (2005) finds a positive relationship between this measure and the probability for self-employment, citing this as evidence for the 'jack-of-all-trades' hypothesis (Lazear, 2004; 2005).

We analyze a sample of individuals attempting to establish a business. Here the relevant question is not whether multi-skilled individuals are more likely to become self-employed or business owners, but whether they are more likely to succeed when trying to set up a business. This is a very different question than that asked in previous studies, since the primary threshold, the decision to start a business, has already been made. Furthermore, our sample differs from that of Lazear (2005) in that it is not restricted to graduates of a university, but comes from a representative selection of the Dutch and German population of nascent entrepreneurs.

It is certainly a challenge to assess the variety of skills a person masters and even more so to judge how balanced these skills are. We did the former 
by posing a question consisting of a list of eight items. The interviewees where asked about how many years of experience they had in each of eight fields. These fields are: design/engineering, production, marketing/sales, finance/accounting, legal, human resources, general management and consultancy. We use this variable as a continuous variable for skill variety, but we also constructed three dummies for low, medium and high skill variety. If they had a least a full year of experience in a field, we rated this as experienced $(=1)$ and aggregated the nine items (0-8) into a tree-staged dummy-variable which we label 'low skill variety' in case one has experience in less than three fields, 'medium skill variety' if one has experience in three to five fields and 'high skill variety' in case the interviewee has experience in six to eight fields.

In order to judge how balanced the nascent entrepreneurs' skills are we choose to rely on self-assessment. A personal assessment has the advantage over any approach to examine the balance of knowledge objectively in that it considers the individual's perception. This is important, since the individual's perception of his or her own abilities is of great importance for the likelihood to try to become self-employed (Simon et al., 2000). After posing the questions about the fields of experience used for assessing the variety of skills, a simple question was asked whether the interviewees would choose to describe themselves overall more as being a generalist or more as being a specialist in one specific area.

According to Lazear (2005) individuals who plan to start a new business should intentionally choose to acquire more varied skills than those who do not. Table 2 shows that 56 per cent of our sample claims to have experience in 3 to 8 fields, while 44 percent has experience in 0 to 2 fields. Furthermore 6 percent would describe themselves more as a generalist. Table 2 shows that those who claim to be generalists more often than specialists have experience in some or many fields, and less often master only a few fields. Almost half (44 percent) of the specialists interviewed claims to have gained experience in three or more different fields. Furthermore, more than one thirds of the generalists have experience in two fields or less only. The correlation between the skill balance dummy and the continuous skill variety variable is as low as 0.09 , supporting our view that balance and variety of skills is not necessarily similar.

As a side-condition for his model Lazear (2005) stated that the model might not apply for solo-entrepreneurs since their firms often tend to be focused on 
Table 2: Skill balance and skill variety

\begin{tabular}{lccc}
\hline $\begin{array}{l}\text { Number of fields of } \\
\text { experience }\end{array}$ & $\begin{array}{c}\text { Skill balance: } \\
\text { Specialist }\end{array}$ & $\begin{array}{c}\text { Skill balance: } \\
\text { Generalist }\end{array}$ & Skill variety \\
\hline Few $(0-2)$ & 56 & 36 & 44 \\
Some $(3-5)$ & 35 & 47 & 43 \\
Many $(6-8)$ & 8 & 16 & 13 \\
\hline Total & $100(\mathrm{n}=71)$ & $100(\mathrm{n}=118)$ & $100(\mathrm{n}=189)$ \\
\hline
\end{tabular}

a specific skill. We control for this by including a dummy variable indicating whether one is a solo-entrepreneur or not. Being a solo-entrepreneur is characterized by three criteria: not having a partner, not employing others (that also includes sub-contractors according to the rather strict GEM-definition) and not wishing to employ someone within the coming five years. According to these criteria 13 percent of all nascent entrepreneurs in our sample can be classified as solo-entrepreneurs.

\subsection{Estimation Strategy and Results}

Our estimation strategy is to test whether the variety (and balance) of skills and the innovativeness of the planned start-up influence the probability to successfully terminate the entrepreneurial process by establishing the business. To this end we use a multinomial logit model. The outcome of the start-up attempt one year after the initial screening is the dependent variable, and can take the values of either being founded, postponed, or givenup. The independent variables are as described variables measuring skill balance, skill variety, and including dummy variables for product innovation and process innovation. Additionally we include several variables to control for heterogeneity at the individual level, including age, sex, and education. A description of all the variables is given in Table 3 .

We first test whether skill variety (and skill balance) matter for starting-up a new business successfully (Hypothesis 1 ). Table 4 includes the continuous skill variety variable and the skill balance variable and we find no significant relationship between either of these measures and success in getting the business founded. When we use the skill variety dummies (see Table 5), however, it can be seen that there is a significant and positive correlation between having a high skill variety (as opposed to a low skill variety) and start-up success $(\mathrm{p}>0.05)$. This confirms Hypothesis 1. In addition we find 
Table 3: Dependent, independent and control variables

\begin{tabular}{lll}
\hline Variable & Description & Reference Category/ Range \\
\hline Dependent variable & \\
Start-up success & Categorical: \\
& - Business started in follow-up survey (1 year after first contract) \\
& - Start-up attempt postponed \\
& - Start-up attempt abandoned/given up \\
\hline
\end{tabular}

\section{Independent variables}

Skill variety

Skill balance

Product Innovation

Process innovation
Two measures (metric and dummies):

- Number of fields (0-8) in which the respondent has at least one year experience

- Three dummies based on the number of fields in which the respondent has at least one year experience: 0-2 (Low skill variety), 3-5 (Medium skill variety), 6-8 (High skill variety)

Dummy indicating whether the respondent considers himself more of a generalist as opposed to more of a specialist

Dummy for introduction of products or services that are new to all or some customers

Dummy for age of production technology used.
Metric

Low skill variety

Specialist

Product or service new to none of the customers

Production technology used more than 5 years old

\section{Control variables}

Education

Age, Age $\left(^{2}\right)$

Woman

Industry Experience $\left({ }^{2}\right)$

Recent employment

Prior start-up experience

Asked for advice

Solo-entrepreneur

High growth ambition

Investments $>10,000$

Industry

Country

Year of screening
Three dummies (low, medium and high) for level of education of the respondent

Age of the respondent in years (squared)

Dummy for gender of the respondent

Number of months that the respondent has experience in the same industry/area (ln), (squared)

Dummy for whether the respondent worked as an employee in the recent past just before (attempting to) founding the business Dummy for whether the respondent has prior experience with founding a business

Dummy indicating whether the respondent has sought professional advice for establishing the business

Dummy indicating that the respondent does not have a business partner, does not employ others (this includes sub-contractors) and does not wish to employ someone within the coming five years

Dummy indicating the growth expectations of the start-up in terms of revenues

Dummy for the respondents (intended) amount of investments

Dummy for industry with the biggest share

Dummy for "industry not yet known"

Dummy for the Netherlands

Dummy for 2007
High education (university degree or higher)

Metric

Man

Metric

Not employed before

No prior start-up experience

No professional advice sought

Without business partner(s) and employees, and does not wish to employ someone within the next five years

Below average growth expectations

(Intended) investments 10,000 or lower

Real estate, renting and business activities

Germany 2006 
a significant negative relationship between high skill variety and abandoning or giving up the start-up suggesting that skill variety reduces such outcomes. One tentative explanation is that higher skill variety can lead to prospective entrepreneurs discovering their own talents, and hence discourage them from especially non-innovative start ups. The results in Tables 4 and 5 also reveal that being a generalist or having skill balance, which interestingly has a negative sign, does not seem to relate significantly to start-up success.

Considering the control variables we can note that there are a number of variables that are significantly related to our dependent variable. Entrepreneurs with a medium level of education (as compared to those with a high level of education) are more likely to succeed in getting their business founded. This finding reflects the fact that better educated individuals have a wider range of alternative wage-employment options. Having siome recent experience in wage-employment furthermore increases the probability of establishing a business. This may suggest that up-to-date employment experience equip individuals with specific knowledge, experience, skills and networks that are useful in the start-up process.

Intriguingly, it appears that those who sought professional advice are less likely to succeed in their start-up attempts. While we do not have a clear-cut explanation for this it could be a sign of uncertainty or lack of knowledge or experience when someone is looking for external advice. Alternatively, seeking professional advice could also be indicative for more complex start-up attempts and therefore result in a lower likelihood to succeed in establishing a business.

Finally, it can also be seen that some of the factors associated with an increased likelihood of being a business owner or self-employed (e.g. gender and having prior start-up experience) do not seem to matter for being successful in the start-up process.

In Tables 4 and 5 product and process innovation are included as control variables, given Hypothesis 2. It can be seen that innovation by itself does not seem to matter for start-up success. In the next tables we will include interaction terms for skill variety and skill balance on the one hand, and product and process innovation on the other hand, to evaluate whether innovation positively moderates the relationship of skill variety and skill balance and start-up success. 
In Table 6 the interaction term for skill variety and product innovation is included, while Table 7 includes the interaction term for skill variety and process innovation. In accordance with our expectations (Hypothesis 2) we find support that product innovation, as well as process innovation, positively moderate the relationship between skill variety and start-up success.

If skill variety differs from skill balance than the moderating effect of innovation does not necessarily apply to skill balance. Table 8 and 9 indeed reveal that neither the coefficients/marginal effects of the interaction terms for skill balance and product innovation nor for skill balance and process innovation are significant.

Table 4: Multinomial logit results for start-up success with skill variety (metric) and skill balance included

\begin{tabular}{|c|c|c|c|c|c|c|c|c|c|}
\hline & \multicolumn{3}{|c|}{ Business Founded } & \multicolumn{3}{|c|}{ Postponed } & \multicolumn{3}{|c|}{ Given-up } \\
\hline & $\mathrm{dy} / \mathrm{d}$ & $z$ & $\mathrm{P}>|z|$ & $\mathrm{dy} / \mathrm{dx}$ & $\mathrm{z}$ & $\mathrm{P}>|z|$ & $\mathrm{dy} / \mathrm{d}$ & $\mathrm{dx} \quad \mathrm{z}$ & $\mathrm{P}>|z|$ \\
\hline Skill variety & 0.02 & 1.18 & 0.238 & 0.00 & -0.03 & 0.973 & -0.02 & -156 & 0.119 \\
\hline Skill balance & -0.11 & -1.42 & 0.155 & 0.08 & 1.26 & 0.209 & 0.02 & 0.42 & 0.674 \\
\hline Woman & -0.00 & -0.04 & 0.967 & -0.04 & -0.47 & 0.641 & 0.04 & 0.61 & 0.540 \\
\hline Medium education & 0.17 & 2.33 & 0.020 & -0.12 & -1.76 & 0.079 & -0.06 & -0.91 & 0.363 \\
\hline Low education & 0.04 & 0.41 & 0.681 & -0.04 & -0.45 & 0.651 & 0.00 & 0.03 & 0.974 \\
\hline Age & -0.02 & -0.73 & 0.463 & -0.01 & -0.59 & 0.557 & 0.03 & 1.01 & 0.313 \\
\hline $\mathrm{Age}^{2}$ & 0.00 & 1.15 & 0.248 & 0.00 & 0.43 & 0.664 & 0.00 & -1.23 & 0.220 \\
\hline Industry exp. (yrs) & 0.02 & 1.48 & 0.138 & 0.01 & 1.02 & 0.307 & -0.03 & -2.80 & 0.005 \\
\hline Industry exp. ${ }^{2}$ & 0.00 & -1.92 & 0.055 & 0.00 & -0.97 & 0.333 & 0.00 & 3.18 & 0.001 \\
\hline Recent employment exp. & 0.24 & 2.71 & 0.007 & -0.21 & -2.87 & 0.004 & -0.03 & -0.37 & 0.709 \\
\hline Prior start-up exp. & -0.06 & -0.75 & 0.454 & 0.01 & 0.14 & 0.889 & 0.05 & 0.78 & 0.435 \\
\hline Asked for advice & -0.04 & -2.59 & 0.010 & 0.03 & 1.63 & 0.102 & 0.02 & 1.31 & 0.189 \\
\hline Solo-entrepreneur & 0.03 & 0.26 & 0.793 & -0.09 & -0.88 & 0.376 & 0.05 & 0.42 & 0.671 \\
\hline High growth ambition & -0.08 & -1.11 & 0.268 & 0.00 & 0.02 & 0.983 & 0.08 & 1.63 & 0.103 \\
\hline Investments $>10,000$ & -0.05 & -0.58 & 0.560 & 0.01 & 0.17 & 0.867 & 0.03 & 0.60 & 0.547 \\
\hline
\end{tabular}

Notes: Industry, country and year dummy/dummies included, but not reported. 
Table 5: Multinomial logit results for start-up success with skill variety dummies and skill balance included

\begin{tabular}{lrrrrrrrrr}
\hline & \multicolumn{3}{c}{ Business Founded } & \multicolumn{3}{c}{ Postponed } & \multicolumn{3}{c}{ Given-up } \\
& $\mathrm{dy} / \mathrm{dx}$ & $\mathrm{z}$ & $\mathrm{P}>|z|$ & $\mathrm{dy} / \mathrm{dx}$ & $\mathrm{z}$ & $\mathrm{P}>|z|$ & $\mathrm{dy} / \mathrm{dx}$ & $\mathrm{z}$ & $\mathrm{P}>|z|$ \\
& & & & & & & & & \\
High skill variety & 0.26 & 2.07 & 0.038 & -0.01 & -0.07 & 0.944 & -0.25 & -2.14 & 0.032 \\
Medium skill variety & 0.03 & 0.37 & 0.712 & -0.06 & -0.91 & 0.365 & 0.03 & 0.59 & 0.558 \\
Skill balance & -0.11 & -1.45 & 0.147 & 0.09 & 1.31 & 0.189 & 0.02 & 0.38 & 0.701 \\
Medium education & 0.18 & 2.50 & 0.013 & -0.11 & -1.76 & 0.079 & -0.07 & -1.10 & 0.270 \\
Low education & 0.03 & 0.30 & 0.765 & -0.04 & -0.50 & 0.618 & 0.02 & 0.25 & 0.806 \\
Age & -0.02 & -0.87 & 0.382 & -0.01 & -0.50 & 0.618 & 0.03 & 1.13 & 0.257 \\
Age & 0.00 & 1.33 & 0.183 & 0.00 & 0.34 & 0.732 & 0.00 & -1.39 & 0.165 \\
Woman & -0.01 & -0.08 & 0.939 & -0.04 & -0.59 & 0.555 & 0.05 & 0.85 & 0.394 \\
Industry exp. (yrs) & 0.01 & 1.32 & 0.188 & 0.01 & 0.98 & 0.328 & -0.02 & -2.71 & 0.007 \\
Industry exp. & 0.00 & -1.82 & 0.070 & 0.00 & -0.95 & 0.344 & 0.00 & 3.22 & 0.001 \\
Recent employment exp. & 0.24 & 2.77 & 0.006 & -0.19 & -2.66 & 0.008 & -0.05 & -0.67 & 0.501 \\
Prior start-up exp. & -0.08 & -1.04 & 0.297 & 0.02 & 0.31 & 0.757 & 0.06 & 1.03 & 0.302 \\
Asked for advice & -0.04 & -2.42 & 0.016 & 0.03 & 1.78 & 0.075 & 0.01 & 0.89 & 0.372 \\
Solo-entrepreneur & 0.02 & 0.12 & 0.903 & -0.09 & -0.90 & 0.368 & 0.07 & 0.55 & 0.582 \\
High growth ambition & -0.11 & -1.47 & 0.142 & 0.00 & -0.02 & 0.984 & 0.12 & 2.27 & 0.024 \\
Investments > 10,000 & -0.04 & -0.58 & 0.564 & 0.01 & 0.12 & 0.901 & 0.03 & 0.71 & 0.475 \\
\hline
\end{tabular}

Notes: Industry, country and year dummy/dummies included, but not reported.

Table 6: Multinominal logit results for start-up success with interaction terms for skill variety (metric) and product innovation included

\begin{tabular}{lrrrrrrrrr}
\hline & \multicolumn{3}{c}{ Business Founded } & \multicolumn{3}{c}{ Postponed } & \multicolumn{3}{c}{ Given-up } \\
& \multicolumn{1}{c}{$\mathrm{dy} / \mathrm{dx}$} & $\mathrm{z}$ & $\mathrm{P}>|z|$ & $\mathrm{dy} / \mathrm{dx}$ & $\mathrm{z}$ & $\mathrm{P}>|z|$ & $\mathrm{dy} / \mathrm{dx}$ & $\mathrm{z}$ & $\mathrm{P}>|z|$ \\
Skill variety & -0.03 & -1.42 & 0.154 & 0.03 & 1.08 & 0.280 & 0.00 & 0.18 & 0.860 \\
Skill balance & -0.09 & -1.24 & 0.216 & 0.07 & 1.05 & 0.293 & 0.02 & 0.38 & 0.700 \\
Product innovation & -0.35 & -3.13 & 0.002 & 0.19 & 1.64 & 0.102 & 0.15 & 1.59 & 0.112 \\
Process innovation & -0.04 & -0.53 & 0.597 & -0.01 & -0.12 & 0.906 & 0.05 & 0.89 & 0.372 \\
Skill variety x prod. in. & 0.10 & 3.30 & 0.001 & -0.06 & -1.91 & 0.056 & -0.04 & -1.45 & 0.146 \\
Medium education & 0.16 & 2.29 & 0.022 & -0.11 & -1.62 & 0.104 & -0.05 & -0.89 & 0.373 \\
Low education & 0.03 & 0.30 & 0.761 & -0.04 & -0.40 & 0.690 & 0.01 & 0.12 & 0.904 \\
Age & -0.03 & -0.95 & 0.344 & -0.01 & -0.29 & 0.774 & 0.03 & 1.04 & 0.300 \\
Age 2 & 0.00 & 1.32 & 0.187 & 0.00 & 0.16 & 0.875 & 0.00 & -1.25 & 0.212 \\
Woman & -0.01 & -0.15 & 0.884 & -0.03 & -0.38 & 0.701 & 0.04 & 0.64 & 0.520 \\
Industry exp. (yrs) & 0.02 & 1.55 & 0.121 & 0.01 & 0.96 & 0.338 & -0.03 & -2.95 & 0.003 \\
Industry exp. & 0.00 & -1.95 & 0.051 & 0.00 & -0.89 & 0.371 & 0.00 & 3.31 & 0.001 \\
Recent employment exp. & 0.24 & 2.65 & 0.008 & -0.21 & -2.89 & 0.004 & -0.02 & -0.36 & 0.715 \\
Prior start-up exp. & -0.06 & -0.82 & 0.412 & 0.01 & 0.21 & 0.837 & 0.04 & 0.79 & 0.430 \\
Asked for advice & -0.04 & -2.59 & 0.010 & 0.03 & 1.65 & 0.098 & 0.02 & 1.18 & 0.237 \\
Solo-entrepreneur & 0.02 & 0.15 & 0.882 & -0.08 & -0.78 & 0.437 & 0.06 & 0.46 & 0.644 \\
High growth ambition & -0.06 & -0.81 & 0.418 & -0.02 & -0.22 & 0.828 & 0.07 & 1.53 & 0.127 \\
Investments > 10,000 & -0.04 & -0.55 & 0.579 & 0.01 & 0.16 & 0.871 & 0.03 & 0.55 & 0.580 \\
\hline
\end{tabular}

Notes: Industry, country and year dummy/dummies included, but not reported. 
Table 7: Multinominal logit results for start-up success with an interaction term for skill variety (metric) and process innovation included

\begin{tabular}{|c|c|c|c|c|c|c|c|c|c|}
\hline & \multicolumn{3}{|c|}{ Business Founded } & \multicolumn{3}{|c|}{ Postponed } & \multicolumn{3}{|c|}{ Given-up } \\
\hline & dy $/ c$ & $\mathrm{z}$ & $\mathrm{P}>|z|$ & $\mathrm{dy} / \mathrm{dx}$ & $\mathrm{z}$ & $\mathrm{P}>|z|$ & $\mathrm{dy} / \mathrm{dx}$ & $z$ & $\mathrm{P}>|z|$ \\
\hline Skill variety & -0.01 & -0.40 & 0.689 & 0.02 & 0.86 & 0.391 & -0.01 & -0.57 & 0.571 \\
\hline Skill balance & -0.10 & -1.45 & 0.148 & 0.07 & 1.14 & 0.256 & 0.03 & 0.52 & 0.604 \\
\hline Product innovation & -0.10 & -1.29 & 0.198 & 0.04 & 0.57 & 0.572 & 0.05 & 0.88 & 0.378 \\
\hline Process innovation & -0.41 & -2.86 & 0.004 & 0.22 & 1.61 & 0.107 & 0.19 & 2.03 & 0.043 \\
\hline Skill variety $\mathrm{x}$ proc. in. & 0.12 & 3.18 & 0.001 & -0.08 & -2.06 & 0.040 & -0.04 & -1.62 & 0.105 \\
\hline Medium education & 0.17 & 2.41 & 0.016 & -0.12 & -1.75 & 0.079 & -0.06 & -0.95 & 0.344 \\
\hline Low education & 0.07 & 0.84 & 0.401 & -0.06 & -0.72 & 0.469 & -0.01 & -0.17 & 0.865 \\
\hline Age & -0.02 & -0.87 & 0.386 & -0.01 & -0.35 & 0.727 & 0.03 & 0.98 & 0.327 \\
\hline $\mathrm{Age}^{2}$ & 0.00 & 1.31 & 0.190 & 0.00 & 0.20 & 0.845 & 0.00 & -1.21 & 0.225 \\
\hline Woman & -0.01 & -0.08 & 0.935 & -0.03 & -0.40 & 0.687 & 0.04 & 0.58 & 0.560 \\
\hline Industry exp. (yrs) & 0.02 & 1.53 & 0.127 & 0.01 & 1.00 & 0.317 & -0.03 & -2.81 & 0.005 \\
\hline Industry exp. ${ }^{2}$ & 0.00 & -2.09 & 0.037 & 0.00 & -0.81 & 0.417 & 0.00 & 3.24 & 0.001 \\
\hline Recent employment exp. & 0.25 & 2.85 & 0.004 & -0.21 & -2.97 & 0.003 & -0.03 & -0.47 & 0.636 \\
\hline Prior start-up exp. & -0.09 & -1.29 & 0.196 & 0.03 & 0.43 & 0.671 & 0.06 & 1.08 & 0.278 \\
\hline Asked for advice & -0.04 & -2.81 & 0.005 & 0.03 & 1.63 & 0.103 & 0.02 & 1.40 & 0.162 \\
\hline Solo-entrepreneur & 0.08 & 0.65 & 0.515 & -0.13 & -1.27 & 0.204 & 0.05 & 0.37 & 0.712 \\
\hline High growth ambition & -0.06 & -0.80 & 0.424 & -0.02 & -0.22 & 0.826 & 0.07 & 1.52 & 0.130 \\
\hline Investments $>10,000$ & -0.07 & -0.95 & 0.342 & 0.03 & 0.43 & 0.667 & 0.04 & 0.74 & 0.458 \\
\hline
\end{tabular}

Notes: Industry, country and year dummy/dummies included, but not reported.

Table 8: Multinomial regression results for start-up success with an interaction term for skill balance and product innovation included

\begin{tabular}{|c|c|c|c|c|c|c|c|c|c|}
\hline & \multicolumn{3}{|c|}{ Business Founded } & \multicolumn{3}{|c|}{ Postponed } & \multicolumn{3}{|c|}{ Given-up } \\
\hline & $\mathrm{dy} / \mathrm{d}$ & $\mathrm{x} \quad \mathrm{z}$ & $\mathrm{P}>|z|$ & $\mathrm{dy} / \mathrm{dx}$ & $\mathrm{z}$ & $\mathrm{P}>|z|$ & $\mathrm{dy} / \mathrm{dx}$ & $\mathrm{z}$ & $\mathrm{P}>|z|$ \\
\hline Skill variety & 0.02 & 1.20 & 0.231 & 0.00 & 0.09 & 0.927 & -0.02 & -1.81 & 0.070 \\
\hline Skill balance & -0.24 & -2.28 & 0.023 & -0.04 & -0.35 & 0.727 & 0.28 & 2.15 & 0.031 \\
\hline Product innovation & -0.20 & -1.50 & 0.133 & -0.10 & -0.79 & 0.430 & 0.30 & 2.26 & 0.024 \\
\hline Process innovation & 0.00 & -0.03 & 0.975 & -0.04 & -0.57 & 0.570 & 0.05 & 0.83 & 0.408 \\
\hline Skill balance $\mathrm{x}$ prod. in. & 0.18 & 1.20 & 0.230 & 0.16 & 1.23 & 0.217 & -0.34 & -2.47 & 0.013 \\
\hline Medium education & 0.18 & 2.38 & 0.017 & -0.11 & -1.73 & 0.084 & -0.06 & -1.06 & 0.290 \\
\hline Low education & 0.04 & 0.38 & 0.703 & -0.04 & -0.44 & 0.662 & 0.00 & 0.05 & 0.962 \\
\hline Age & -0.02 & -0.83 & 0.407 & -0.02 & -0.79 & 0.430 & 0.04 & 1.18 & 0.240 \\
\hline $\mathrm{Age}^{2}$ & 0.00 & 1.23 & 0.218 & 0.00 & 0.65 & 0.517 & 0.00 & -1.37 & 0.172 \\
\hline Woman & -0.02 & -0.21 & 0.835 & -0.04 & -0.54 & 0.592 & 0.06 & 0.98 & 0.328 \\
\hline Industry exp. (yrs) & 0.02 & 1.36 & 0.172 & 0.01 & 1.10 & 0.273 & -0.03 & -2.71 & 0.007 \\
\hline Industry exp. ${ }^{2}$ & 0.00 & -1.78 & 0.076 & 0.00 & -1.12 & 0.262 & 0.00 & 2.99 & 0.003 \\
\hline Recent employment exp. & 0.26 & 2.78 & 0.005 & -0.20 & -2.81 & 0.005 & -0.06 & -0.82 & 0.414 \\
\hline Prior start-up exp. & -0.06 & -0.74 & 0.459 & 0.01 & 0.12 & 0.908 & 0.05 & 0.84 & 0.401 \\
\hline Asked for advice & -0.05 & -2.70 & 0.007 & 0.02 & 1.51 & 0.132 & 0.02 & 1.76 & 0.078 \\
\hline Solo-entrepreneur & 0.03 & 0.23 & 0.816 & -0.10 & -1.01 & 0.312 & 0.07 & 0.54 & 0.586 \\
\hline High growth ambition & -0.09 & -1.19 & 0.236 & 0.00 & -0.05 & 0.961 & 0.10 & 1.89 & 0.058 \\
\hline Investments $>10,000$ & -0.05 & -0.66 & 0.510 & -0.01 & -0.07 & 0.945 & 0.06 & 1.00 & 0.318 \\
\hline
\end{tabular}

Notes: Industry, country and year dummy/dummies included, but not reported. 
Table 9: Multinominal logit results for start-up success with an interaction term for skill balance and process innovation included

\begin{tabular}{lrrrrrrrrr}
\hline & \multicolumn{1}{c}{ Busines Founded } & \multicolumn{3}{c}{ Postponed } & \multicolumn{3}{c}{ Given-up } \\
& $\mathrm{dy} / \mathrm{dx}$ & $\mathrm{z}$ & $\mathrm{P}>|z|$ & $\mathrm{dy} / \mathrm{dx}$ & $\mathrm{z}$ & $\mathrm{P}>|z|$ & $\mathrm{dy} / \mathrm{dx}$ & $\mathrm{z}$ & $\mathrm{P}>|z|$ \\
& & & & & & & & & \\
Skill variety & 0.02 & 1.18 & 0.239 & 0.00 & 0.01 & 0.995 & -0.02 & -1.57 & 0.117 \\
Skill balance & -0.12 & -1.49 & 0.135 & 0.06 & 0.83 & 0.404 & 0.06 & 0.83 & 0.408 \\
Product innovation & -0.07 & -0.90 & 0.367 & 0.02 & 0.29 & 0.774 & 0.05 & 0.78 & 0.435 \\
Process innovation & -0.02 & -0.11 & 0.911 & -0.10 & -0.72 & 0.470 & 0.12 & 1.21 & 0.228 \\
Skill balance x proc. in. & 0.03 & 0.18 & 0.856 & 0.08 & 0.49 & 0.623 & -0.11 & -0.95 & 0.342 \\
Medium education & 0.17 & 2.31 & 0.021 & -0.12 & -1.84 & 0.066 & -0.05 & -0.80 & 0.423 \\
Low education & 0.04 & 0.40 & 0.688 & -0.04 & -0.48 & 0.634 & 0.01 & 0.07 & 0.943 \\
Age & -0.02 & -0.73 & 0.468 & -0.01 & -0.58 & 0.562 & 0.03 & 0.97 & 0.333 \\
Age & 0.00 & 1.13 & 0.529 & 0.00 & 0.43 & 0.667 & 0.00 & -1.17 & 0.242 \\
Woman & 0.00 & -0.05 & 0.963 & -0.03 & -0.42 & 0.675 & 0.04 & 0.56 & 0.578 \\
Industry exp. (yrs) & 0.02 & 1.44 & 0.149 & 0.01 & 1.03 & 0.303 & -0.03 & -2.72 & 0.007 \\
Industry exp. & 0.00 & -1.87 & 0.062 & 0.00 & -0.99 & 0.323 & 0.00 & 3.02 & 0.003 \\
Recent employment exp. & 0.24 & 2.68 & 0.007 & -0.21 & -2.91 & 0.004 & -0.03 & -0.42 & 0.674 \\
Prior start-up exp. & -0.05 & -0.71 & 0.480 & 0.01 & 0.14 & 0.885 & 0.04 & 0.73 & 0.465 \\
Asked for advice & -0.05 & -2.64 & 0.008 & 0.02 & 1.58 & 0.115 & 0.02 & 1.48 & 0.138 \\
Solo-entrepreneur & 0.03 & 0.23 & 0.820 & -0.09 & -0.90 & 0.367 & 0.06 & 0.49 & 0.622 \\
High growth ambition & -0.09 & -1.11 & 0.268 & 0.00 & 0.06 & 0.951 & 0.08 & 1.55 & 0.121 \\
Investments > 10,000 & -0.05 & -0.64 & 0.525 & 0.01 & 0.09 & 0.926 & 0.04 & 0.76 & 0.448 \\
\hline
\end{tabular}

Notes: Industry, country and year dummy/dummies included, but not reported. 


\section{Concluding Remarks}

In this paper we contributed in three ways towards extending Lazear's theory of skills diversity and entrepreneurship. First, we explicitly linked entrepreneurial skills to opportunities as an explanation for the rate of new business creation. We proposed a theoretical model to show that opportunities, skills and innovation interact to result in the creation of innovative new businesses. Second, we refined the 'jack-of-all-trades' concept to allow for generalists and specialists to possess a variety of skills through their experiences and/or investments in human capital. In other words, entrepreneurs can have a variety of skills even as they specialize. Our third contribution was to test our model, in particular to provide empirical evidence on the interaction between an individual's experience and skills on the one hand, and his or her attempt to introduce a new product and/or service or a business process innovation, on the other.

To test our model we use survey data collected among nascent entrepreneurs in Germany and the Netherlands, supplemented by follow-up interviews one year after the first contact. Applying multinomial probit estimations, our main finding is that skill variety (high skill variety as opposed to low skill variety) improves start-up success, while skill balance does not. Furthermore it is found that prospective entrepreneur's skill variety in particular facilitates the establishment of innovative new business.

The main insights from this paper are as follows. Individuals with more varied work experience are more likely to succeed in starting up a new business. Having experience in a variety of areas seems to facilitate the creation of a new business. This does not mean however that those with varied skills are necessarily 'more balanced individuals' (Lazear, 2005: 676) as they may still excel in one specific skill. As a matter of fact our empirical results show that being a generalist, which proxies having balanced skills, does not matter for success in setting up a business. This confirms our hypothesis that having varied work experience does not necessarily imply that someone is a specialist and vice versa. We find that this holds in particular for those attempting to set up an innovative business (i.e. introducing new products or services to the market; and/or introducing new business processes).

Thus, innovation positively moderates the relationship between having varied experience and success in setting up a business. Those with skill variety are better positioned to introduce innovations that not only have technical, 
but also commercial value.

The policy implications from this paper are first that entrepreneurial education and business environment reform need to be tackled jointly and coordinated to improve matching between various skills and competencies on the one hand, and opportunities on the other. Second, our findings support the notion that entrepreneurship can, at least partly, be learned, and that learning by doing and experiential learning, matters. These implications supports Cukier's (2006:11) call for public policy toward entrepreneurship to be more like 'the very thing it hopes to promote- and embrace risk, experimentation and diversity'. Such an approach could broaden the experience of prospective entrepreneurs. Finally, given that more varied work experience is associated with start-up success, promotion of more flexible labor markets and active labor policies that promote youth employment seem to be supported by the model and evidence in this paper. Such institutional

reforms require however, as Lerner (2010) also stressed, persistence and a long-term commitment of policy makers towards entrepreneurship.

\section{Acknowledgements}

We are grateful to Thomas Schøtt and Miguel Meuleman who provided valuable input for the design of the questionnaire.

\section{References}

[1] Ács, Z.J. and Naudé W.A. (2013). 'Entrepreneurship, Stages of Development, and Industrialization', (In Szirmai, A., Naudé, W.A. and Alcorta, L. (eds.). Pathways to Industrialization in the Twenty-First Century. Oxford: Oxford University Press. Chapter 14, pp. 373-392.)

[2] Åstebro, T. and Bernhardt. I. (2005). 'The Winner's Curse of Human Capital', Small Business Economics, 24: 63-78.

[3] Åstebro, A., and Thompson, P. (2011). 'Entrepreneurs, Jacks of all trades or Hobos?', Research Policy, 40: 637-649.

[4] Baptista, R., Karaöz, M. and Mendonca, J. (2007). 'Entrepreneurial Backgrounds, Human Capital and Start-Up Success', Jena Economic Research Papers 2007-045, Jena: Max Planck Institute of Economics and Friedrich Schiller University. 
[5] Braunerhjelm, P., Ács, Z.J., Audretsch, D.B., and Carlsson, B., (2010). 'The Missing Link: Knowledge Diffusion and Entrepreneurship in Endogenous Growth,' Small Business Economics, 34 (2): 105-125.

[6] Brüderl, J., and Schüssler, R. (1990). 'Organizational mortality: The liabilities of newness and adolescence', Administrative Science Quarterly, 35: $530-547$.

[7] Bruhn, M. and Zia, B. (2011). 'Stimulating Managerial Capital in Emerging Markets: The Impact of Business and Financial Literacy for Young Entrepreneurs', Policy Research Working Paper no. 5642. Washington DC. The World Bank.

[8] Bublitz, E., and Noseleit, F. (2013). 'The skill balancing act: when does broad expertise pay off?' Small Business Economics, forthcoming, doi10.1007/s11187-013-9474-z

[9] Carter, N. M., Gartner, W. B., and Reynolds, P. D. (2004). 'Firm founding'. (In Gartner W. B., Shaver K. G., Carter N. M., and P. D. Reynolds (eds.). Handbook of Entrepreneurial Dynamics. Thousand Oaks, London: Sage, pp. 311-323.)

[10] Cukier, K. (2006). Innovative Entrepreneurship and Public Policy: Hero with a Thousand Faces. Swiss Re.

[11] Evans, D.S. and Jovanovic, B. (1989). 'An Estimated Model of Entrepreneurial Choice under Liquidity Constraints', Journal of Political Economy, 97(4): 808-827.

[12] Freeman, J., Carroll, G.R., and Hannan, M.T. (1983). 'The Liability of Newness: Age dependence in organizational death rates', American Sociological Review, 48: 692-710.

[13] Gries, T., and Naudé, W. (2011). 'Entrepreneurship and human development - A capability approach', Journal of Public Economics, 95: 216-224.

[14] Hurst, E., and Pugsley, B.W. (2011). 'What do small businesses do?', Brookings Papers on Economic Activity, Economic Studies Program, The Brookings Institution, 43(2): 73-142.

[15] Karlan, D. and Valdivia, M. (2011). 'Teaching Entrepreneurship: Impact of Business Training on Microfinance Clients and Institutions' The Review of Economics and Statistics, 93 (2): 510-527. 
[16] Katz, J., and Gartner, W.B. (1988). 'Properties of emerging organizations', Academy of Management Review, 13(3): 429-441.

[17] Kanniainen, V. and Poutvaara, P. (2007). 'Imperfect Transmission of Tacit Knowledge and Other Barriers to Entrepreneurship', Comparative Labor Law and Policy Journal, 28: 675-693.

[18] Kihlstrom, R.E. and Laffont, J-J. (1979). 'A General Equilibrium Entrepreneurial Theory of Firm Formation Based on Risk Aversion', Journal of Political Economy, 87(4): 719-748.

[19] Lazear, E.P. (2004). 'Balanced skills and entrepreneurship', American Economic Review, 94(2): 208-211.

[20] Lazear, E.P. (2005). 'Entrepreneurship', Journal of Labor Economics, 23(4): $649-680$.

[21] Lerner, J. (2010). 'The Future of Public Efforts to Boost Entrepreneurship and Venture Capital', Small Business Economics, 35: 255-264.

[22] Lucas, R.E. (1978). 'On the Size Distribution of Business Firms', Bell Journal of Economics, 9: 508-523.

[23] OECD; Eurostat (2005, 3rd edition): Oslo Manual Guidelines for collecting and interpreting innovation data. OECD Publishing.

[24] Parker, S.C. (2009). The Economics of Entrepreneurship. Cambridge (MA): Cambridge University Press.

[25] Pissarides, C. A. (2000). Equilibrium Unemployment Theory. 2nd ed.: MIT Press.

[26] Reynolds, P.D., and Miller, B. (1992). 'New firm gestation: Conception, birth, and implications for research', Journal of Business Venturing, 7: $1-8$.

[27] Silva, O. (2007). 'The Jack-of-All-Trades entrepreneur: Innate talent or acquired skill?' Economics Letters, 97: 118-123.

[28] Simon, M., Houghton, S.M., Aquino, K. (2000). 'Cognitive biases, risk perception, and venture formation: How individuals decide to start companies', Journal of Business Venturing, 15(2): 113-134.

[29] Spulber, D.F. (2009). The Theory of the Firm: Microeconomics with Endogenous Entrepreneurs, Firms, Markets, and Organizations. Cambridge (MA): Cambridge University Press. 
[30] Stuetzer, M., Goethner, M., and Cantner, U. (2012). 'Do balanced skills help nascent entrepreneurs to make progress in the venture creation process?', Economics Letters, 117: 186-188.

[31] Stuetzer, M., Obschonka, M., Davidsson, P., and Schmitt-Rodermund, E. (2013a). 'Where do entrepreneurial skills come from?' Applied Economics Letters, 20(12): 1183-1186.

[32] Stuetzer, M., Obschonka, M., and Schmitt-Rodermund, E. (2013b). 'Balanced skills among nascent entrepreneurs', Small Business Economics, 41(1): 93-114.

[33] Toft-Kehler, R., Wennberg, K. and Kim, P.H. (2013). 'Practice Makes Perfect: Entrepreneurial-Experience Curve and Venture Performance', Journal of Business Venturing, Article in Press.

[34] Wagner, J. (2003). 'Testing Lazear's jack-of-all-trades view of entrepreneurship with German micro data', Applied Economic Letters, 10, 687-689.

[35] Wagner, J. (2006). 'Are nascent entrepreneurs 'Jacks-of-all-trades'? A test of Lazear's theory of entrepreneurship with German data', Applied Economics, 38(20): 2415-2419.

\section{Appendices:}

\subsection{Appendix 1: Determining Optimal Effort Levels}

Search effort: Determining the optimal search effort, the effort function $\eta$, and the derivatives of $\eta$ :

To simplify we may assume symmetry for the value of human capital in each experience $h_{i j}$. Hence $\left(\sum_{j=1}^{\bar{e}_{i}} h_{i j}\right)^{-1}=\left(\bar{e}_{i} h_{i}\right)^{-1}$.

$$
\max _{\eta_{i}}: r W_{i}=w_{i}-\frac{\eta_{i}}{\bar{e}_{i} h_{i}}+\mu \frac{\omega^{\beta}\left(\eta_{i} u\right)^{1-\beta}}{u} \Delta_{i}
$$

First order conditions (FOCs) and second order conditions (SOCs):

$$
0=-\frac{1}{\bar{e}_{i} h_{i}}+\mu \frac{\Delta}{u}(1-\beta) \frac{M}{\eta_{i}}, \quad 0>-\mu \frac{\Delta_{i}}{u}(1-\beta) \beta \omega^{\beta} \eta_{i}^{-\beta-1} u^{1-\beta}
$$


Optimal search effort of each entrepreneur is determined by using the implicit function theorem from the FOCs. and SOCs. We obtain

$$
\eta_{i}^{*}=\eta_{i}^{*}\left(u, \omega, \Delta_{i}, \bar{e}_{i}, \mu\right), \quad \eta_{\Delta_{i}}>0, \quad \eta_{\omega}>0, \quad \eta_{u}<0, \quad \eta_{\bar{e}_{i}}<0, \quad \eta_{\mu}>0
$$

Derivatives of the optimal effort:

$$
\begin{aligned}
\eta_{\Delta_{i}} & =\frac{\eta_{i}}{\Delta_{i} \beta}>0, \quad \eta_{\omega}=\frac{\eta_{i}}{\omega}>0, \quad \eta_{u}=-\frac{\eta_{i}}{u}<0, \\
\eta_{\bar{e}_{i}} & =\frac{1}{\mu \frac{\Delta_{i}}{u}(1-\beta) \beta \frac{M}{\eta_{i}^{2}}} \frac{1}{\bar{e}_{i} h_{i}}>0, \quad \eta_{\mu}=\frac{\eta_{i}}{\mu \beta}>0
\end{aligned}
$$

Stay in market effort: Determining optimal effort to stay in the market, effort function $\psi_{i}$ and derivatives:

$$
\max _{\psi_{i}}: r V_{i}=v_{i}-\gamma_{i} \psi_{i}-\phi_{i}\left(\psi_{i}\right) \Delta_{i}
$$

FOCs and SOCs.

$$
-\gamma_{i}-\phi_{\psi_{i}} \Delta_{i}=0, \quad-\phi_{\psi_{i} \psi_{i}} \Delta_{i}<0
$$

where $\phi_{\psi_{i}}:=\frac{\partial \phi_{i}}{\partial \psi_{i}}$. From the FOCs and SOCs we obtain the optimal strategy

$$
\psi_{i}^{*}=\psi_{i}^{*}\left(\Delta_{i}, \gamma_{i}\right)
$$

with

$$
\frac{\partial \psi_{i}}{\partial \gamma_{i}}=: \psi_{\gamma_{i}}=-\frac{1}{\phi_{\psi_{i} \psi_{i}} \Delta_{i}}<0, \quad \frac{\partial \psi_{i}}{\partial \Delta_{i}}=: \psi_{\Delta}=-\frac{\phi_{\psi_{i}}}{\phi_{\psi_{i} \psi_{i}} \Delta_{i}}>0
$$

\subsection{Appendix 2: Proof of Proposition 1}

Equations $F, G, H[(1),(2),(3)]$ have continuous partial derivatives with respect to all variables. As all variables are positive, and since

$$
\frac{q}{p+q} \Omega-E>0 \rightarrow \omega>u,
$$

the determinant of the Jacobian matrix for the smooth function $f(x, y)=$ $(F, G, H)(x, y), y=(\omega, u, \Delta), x=(\mu, \bar{e}, q, p, \Omega, E, w)$ does not vanish:

$$
A=\left(\begin{array}{ccc}
-\mu \frac{M}{\omega} & -\phi & \phi_{\psi} \psi_{\Delta}(E-u)-\mu(1-\beta) \frac{M}{\Delta \beta} \\
\Delta \mu \beta \frac{m}{\omega} & -\Delta \mu \beta \frac{m}{u} & (r+\phi+\mu m) \\
1 & -1 & 0
\end{array}\right)
$$




$$
|A|=-(r+\phi+\mu m)\left(\phi+\mu \frac{M}{\omega}\right)+\mu\left(\bar{\phi}_{\psi}+\psi_{\Delta}(E-u) \Delta \beta-\mu(1-\beta) M\right)(\underbrace{\frac{m}{u}-\frac{m}{\omega}}_{>0}) \neq 0
$$

So that the Jacobian matrix is invertible and the implicit function theorem can be applied. System [(1), (2), (3)] implicitly defines the functions

$$
\begin{aligned}
u^{*} & =u^{*}(\mu, \bar{e}, h, q, p, \Omega, E, v, w) \\
\omega^{*} & =\omega^{*}(\mu, \bar{e}, h, q, p, \Omega, E, v, w) \\
\Delta^{*} & =\Delta^{*}(\mu, \bar{e}, h, q, p, \Omega, E, v, w) .
\end{aligned}
$$

\subsection{Appendix 3: Proof of Hypothesis 1 and 2}

Comparative statics for the system $F, G, H$ can be performed by taking the partial reaction from $A \partial a=\partial B$, with

$$
\begin{aligned}
\partial a & =(\partial \omega, \partial u, \partial \Delta)^{\prime}, \\
A & =\left(\begin{array}{ccc}
-\mu \frac{M}{\omega} & -\phi & \overline{\phi_{\psi}} \psi_{\Delta}(E-u)-\mu(1-\beta) \frac{M}{\Delta \beta} \\
\Delta \mu \beta \frac{m}{\omega} & -\Delta \mu \beta \frac{m}{u} & (r+\phi+\mu m) \\
1 & -1 & 0
\end{array}\right) \\
\partial B & =\left(\begin{array}{c}
\frac{M}{\beta} \partial \mu-\frac{\eta u}{\Delta \beta} \partial c \\
0 \\
0
\end{array}\right)
\end{aligned}
$$

solving for the effects of the variety of work experiences $\bar{e}$, and matching efficiency $\mu$ on wealth differentials and the number of nascent entrepreneurs gives for $\frac{\partial \Delta^{*}}{\partial \bar{e}}$ and $\frac{\partial \Delta^{*}}{\partial \mu}$,

$$
\begin{aligned}
& \frac{\partial \Delta^{*}}{\partial \bar{e}}=\frac{-\frac{u \eta}{\Delta \beta} \frac{1}{\bar{e}^{2} h}}{\left[\left(\mu \frac{M}{\omega}+\phi\right) \frac{(r+\phi+\mu m)}{\beta \Delta \mu m\left(\frac{1}{u}-\frac{1}{\omega}\right)}-\left((E-u) \phi_{\psi} \psi_{\Delta}-\mu(1-\beta) \frac{M}{\Delta \beta}\right)\right]}<0, \\
& \frac{\partial \Delta^{*}}{\partial \mu}=\frac{-\frac{M}{\beta}}{\left[\left(\mu \frac{M}{\omega}+\phi\right) \frac{(r+\phi+\mu m)}{\beta \Delta \mu m\left(\frac{1}{u}-\frac{1}{\omega}\right)}-\left((E-u) \phi_{\psi} \psi_{\Delta}-\mu(1-\beta) \frac{M}{\Delta \beta}\right)\right]}<0 .
\end{aligned}
$$

and for $\frac{\partial u^{*}}{\partial \bar{e}}$ and $\frac{\partial u^{*}}{\partial \mu}$ 


$$
\begin{aligned}
\frac{\partial u^{*}}{\partial \bar{e}} & =\frac{-\frac{u \eta}{\Delta \beta} \frac{1}{\bar{e}^{2} h}}{\left[\left(\mu \frac{M}{\omega}+\phi\right)-\left((E-u) \phi_{\psi} \psi_{\Delta}-\mu(1-\beta) \frac{M}{\Delta \beta}\right) \frac{\beta \Delta \mu m\left(\frac{1}{u}-\frac{1}{\omega}\right)}{(r+\phi+\mu m)}\right]}<0, \\
\frac{\partial u^{*}}{\partial \mu} & =\frac{-\frac{M}{\beta}}{\left[\left(\mu \frac{M}{\omega}+\phi\right)-\left((E-u) \phi_{\psi} \psi_{\Delta}-\mu(1-\beta) \frac{M}{\Delta \beta}\right) \frac{\beta \Delta \mu m\left(\frac{1}{u}-\frac{1}{\omega}\right)}{(r+\phi+\mu m)}\right]}<0,
\end{aligned}
$$

and for $\frac{\partial \omega^{*}}{\partial \bar{e}}$ and $\frac{\partial \omega^{*}}{\partial \mu}$

$$
\frac{\partial u^{*}}{\partial \bar{e}}=\frac{\partial \omega^{*}}{\partial \bar{e}}, \quad \frac{\partial u^{*}}{\partial \mu}=\frac{\partial \omega^{*}}{\partial \mu}
$$

a) Effects on start-up effort: Changes in search effort $\eta$ are determined by a number of variables $\eta_{i}^{*}=\eta_{i}^{*}\left(u^{*}, \omega^{*}, \Delta^{*}, \bar{e}_{i}, \mu\right)$ :

$$
\begin{aligned}
& \frac{\partial \eta_{i}^{*}}{\partial \bar{e}}=-\frac{\eta_{i}}{u} \frac{\partial u^{*}}{\partial \bar{e}}+\frac{\eta_{i}}{\omega} \frac{\partial \omega^{*}}{\partial \bar{e}}+\frac{\eta_{i}}{\Delta \beta} \frac{\partial \Delta^{*}}{\partial \bar{e}}+\frac{1}{\mu \frac{\Delta}{u}(1-\beta) \beta \frac{M}{\eta_{i}^{2}}} \frac{1}{\bar{e}_{i} h} \\
& =\eta_{i} \frac{\eta_{i}}{\Delta \beta} \frac{1}{\bar{e}^{2} h} \frac{(r+\phi)\left(1-\frac{u}{\omega}\right)}{\left[\begin{array}{c}
\left(\mu \frac{M}{\omega}+\phi\right)(r+\phi+\mu m) \\
-\beta \Delta \mu m\left(\frac{1}{u}-\frac{1}{\omega}\right)\left((E-u) \phi_{\psi} \psi_{\Delta}-\mu(1-\beta) \frac{M}{\Delta \beta}\right)
\end{array}\right]}+\frac{1}{\mu \frac{\Delta}{u}(1-\beta) \beta \frac{M}{\eta_{i}^{2}}} \frac{1}{\bar{e}_{i} h}>0 \\
& \frac{\partial \eta_{i}^{*}}{\partial \mu}=-\frac{\eta_{i}}{u} \frac{\partial u^{*}}{\partial \mu}+\frac{\eta_{i}}{\omega} \frac{\partial \omega^{*}}{\partial \mu}+\frac{\eta_{i}}{\Delta \beta} \frac{\partial \Delta^{*}}{\partial \mu}+\frac{\eta_{i}}{\mu \beta}>0 \\
& =\frac{\eta_{i} \mu}{u \beta} \frac{(r+\phi)\left(1-\frac{u}{\omega}\right)}{\left[\begin{array}{c}
\left(\mu \frac{M}{\omega}+\phi\right)(r+\phi+\mu m) \\
-\beta \Delta \mu m\left(\frac{1}{u}-\frac{1}{\omega}\right)\left((E-u) \phi_{\psi} \psi_{\Delta}-\mu(1-\beta) \frac{M}{\Delta \beta}\right)
\end{array}\right]}+\frac{\eta_{i}}{\mu \beta}>0
\end{aligned}
$$

b) Effects on the separation rate and stationary matching rate:

Changes in the seperation rate $\phi$ :

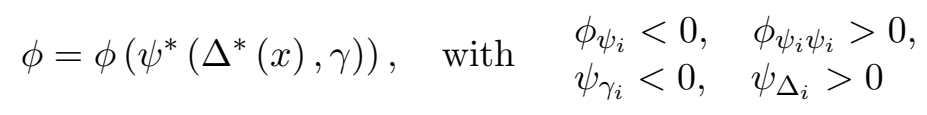


hence from the reaction of $\Delta^{*}$ we obtain:

$$
\begin{aligned}
\frac{\partial \phi^{*}}{\partial \bar{e}}= & \frac{\partial \phi}{\partial \psi^{*}} \frac{\partial \psi^{*}}{\partial \Delta^{*}} \frac{\partial \Delta}{\partial \bar{e}}>0 \\
\frac{\partial \phi^{*}}{\partial \mu}= & \frac{\partial \phi}{\partial \psi^{*}} \frac{\partial \psi^{*}}{\partial \Delta^{*}} \frac{\partial \Delta}{\partial \mu}>0
\end{aligned}
$$

Changes in the matching rate $\varepsilon$ as the percentage of newly started firms $\varepsilon=\frac{\mathcal{M}}{n}$

$$
\varepsilon=\frac{\mathcal{M}}{n}
$$

Under stationary conditions $(\dot{n}=0) \mathcal{M}=\phi n$ and hence $\varepsilon=\phi$. Therefore,

$$
\begin{aligned}
& \frac{\partial \varepsilon^{*}}{\partial \bar{e}}=\frac{\partial \phi^{*}}{\partial \bar{e}}>0 \\
& \frac{\partial \varepsilon^{*}}{\partial \mu}=\frac{\partial \phi^{*}}{\partial \mu}>0 .
\end{aligned}
$$

